\section{Changes in the Respiration, Growth, and Vitamin C Content of Soybean Sprouts in Response to Chitosan of Different Molecular Weights}

\author{
Young-Sang Lee, ${ }^{1}$ Yong-Ho Kim, ${ }^{2}$ and Sung-Bae $\mathrm{Kim}^{3}$ \\ Division of Life Sciences, Soonchunhyang University, 646 Eupnae-ri, \\ Shinchang-myeon, Asan-si, Chungcheongnam-do 336-745, South Korea
}

Additional index words. Glycine max, sprout production, chitosan, quality

\begin{abstract}
To study the effects of chitosan on the productivity and nutritional quality of soybean (Glycine max L.) sprouts, soybean seeds were soaked in solutions containing 1,000 ppm chitosan of low ( $<10 \mathrm{kDa})$, medium (50 to $100 \mathrm{kDa})$, or high ( $>1,000 \mathrm{kDa})$ molecular weight, and the respiration, growth, and vitamin $C$ content of the sprouts were subsequently evaluated. Sprouts treated with high molecular weight chitosan exhibited a significant increase in respiration, $5 \%$, within 1 day of treatment. Chitosan effectively increased the growth of the sprouts: sprouts treated with high molecular weight chitosan showed increases of $3 \%, 1 \%$, $3 \%, 1 \%$, and $12 \%$ in the total length, hypocotyl length, root length, hypocotyl thickness, and fresh weight, respectively, as compared to a control. The growth-improving effects of chitosan were proportional to the molecular weight of the molecule used in the treatment. Chitosan treatment did not result in any significant reduction in vitamin $C$ content or postharvest chlorophyll formation, traits that determine the nutritional and marketing values of soybean sprouts. All these results suggest that soaking soybean seeds in a solution of chitosan, especially of high molecular weight, may effectively enhance the productivity of soybean sprouts without adverse effects on the nutritional and postharvest characteristics.
\end{abstract}

The soybean (Glycine max) sprout, a germinated soybean seed, is a traditional Korean food of great popularity. Soybean sprouts have high nutritional value, as the soybean seed itself contains high levels of proteins and lipids; consequently, soybean sprouts have traditionally been an important source of plant protein in the Korean diet. Moreover, during germination, seed oligosaccharides such as stachyose and raffinose are converted into digestible monosaccharides, and the trypsin inhibitor activity and phytic acid content decrease (Kim et al., 1993). Other important changes in the nutritional value of sprouts during germination are the increases in free amino acids, such as asparagines, and vitamin $\mathrm{C}$, which increases to over 200 times the level found in ungerminated seeds (Kim et al., 1993). Due to their high nutritional value and relatively low price, soybean sprouts are currently the third most highly consumed vegetable in Korea, and soybean sprout production has become an important agricultural business.

Chitosan, derived from the chitin of crab or crustacean shells, is a polymer of 2-amino2-deoxy-D-glucose (glucosamine). Chitosan has been accepted as a natural health food additive, based upon its safety for consumption. Reports are increasing on the use of chitosan for medicinal and industrial food purposes

Received for publication 26 July 2004. Accepted for publication 31 Aug. 2004.

${ }^{1}$ Associate professor. To whom reprint requests should be addressed; e-mail mariolee@sch.ac.kr. ${ }^{2}$ Associate professor.

${ }^{3}$ Researchassistant.Currentaddress:Hankooksamgong, 273-1 Pyungchang-dong, Jongro-ku, Seoul 110-847, South Korea; e-mail schackr76@hotmail.com.
(Park and Kim, 2003). Chitosan also exhibits antimicrobial activity against phytopathogens such as Fusarium solani and F. oxysporum $\mathrm{f}$. sp. cepae, based on the formation of ionic bridges between the positively charged amino group of chitosan and negatively charged sites in the cell walls of microbes (Jeon et al., 1996; Jo, 1989). In a test of the ability of chitosan to reduce soybean sprout rot through its antimicrobial activity, we found that treatment with this highly practical natural compound decreases sprout rot (Lee et al., 1999). In addition, we found that chitosan treatment enhances the yield and marketability of soybean sprouts (Lee et al., 1999). Many reports have described the effects of chitosan on plant metabolism. Chitosan induces the production of chitinase in plant tissues (El Ghaouth et al., 1992) and elicits phytoalexin production (Kendra and Hadwiger, 1984), resulting in antibacterial and antifungal activities that aid the reduction of microbial infections (Bhaskara etal., 2000; Yun et al., 1999). Chitosan has also been reported as stimulating the growth and yield of various crops such as soybean, potato, tomato, and cabbage, enhancing the quality of vegetables; and extending the post-harvest shelf life of fruits (Kim, 1998). However, the precise mechanisms of the enhancement of plant growth by chitosan remain unclear.

Chitosan production involves the deacetylation and enzymatic digestion of chitin into chitosans of lower molecular weights. Varying the degree of digestion and the production method can produce chitosans of different molecular weights, a trait that affects the functionality of the molecule (Kim et al., 2000). The present study was conducted to evaluate the molecular-weight-dependent effects of chitosan on the respiration, growth, and qualitative factors of soybean sprouts, in order to better understand and use chitosan in soybean sprout production.

\section{Materials and Methods}

Plant materials and sprout production. Korean domestic soybean seeds (Glycine max L. 'Junjory') were purchased from the Korean Bean SproutAssociation. Soybean seeds $(1 \mathrm{~kg})$ were soaked in tap water or chitosan-containing treatment solutions for $3 \mathrm{~h}$, transferred into a commercial soybean cultivation vessel of 25 $\times 25 \times 25 \mathrm{~cm}$, and cultivated for $5 \mathrm{~d}$ in a cultivation room equipped with a top-irrigation system. Irrigation was performed for $3 \mathrm{~min}$ every $4 \mathrm{~h}$ using well water of drinking quality. The temperature inside the cultivation room was 20 to $25^{\circ} \mathrm{C}$.

Chitosan treatment and measurement of soaking solution uptake. Stock solutions of chitosan of low (LMW: $<10 \mathrm{kDa}$ ), medium (MMW: 20-50 kDa), or high (HMW: $>1,000$ $\mathrm{kDa}$ molecular weight were purchased from Konong-Nongsan Co. (Seoul, Korea). Stock solutions of three different molecular weights diluted to $1,000 \mathrm{ppm}$ along with tap water of drinking water quality (as a control) were used as soaking solution treatments. After $3 \mathrm{~h}$ of soaking, the soybean seeds were blotted with clean paper, and changes in the seed weight were determined to estimate the amount of soaking solution that had been taken up. Three cultivation vessel replications and completely randomized design were applied for the experiment.

Measurement of sprout growth and yield. During the $5 \mathrm{~d}$ of cultivation, the fresh weight of the sprouts in each cultivation vessel was measured daily. After the $5 \mathrm{~d}, 20$ to 40 representative sprouts were selected from each treatment to measure the growth parameters of hypocotyl thickness, hypocotyl length, root length, and the number of lateral roots. Only lateral roots with lengths greater than $1.0 \mathrm{~mm}$ were counted. The fresh weight was measured by cultivation vessel replication and expressed, based on a dry seed weight of 1,000 g. All experiments were replicated at least three times, and each replication consisted of at least three cultivation vessel subreplications.

Measurement of respiration rate. To measure respiration, $100 \mathrm{~g}$ of hydrated soybean sprouts were placed in a clean gas-tight glass jar equipped with a Teflon-PTFE septum (Wheaton, England). After storage at room temperature for $3 \mathrm{~h}, 1 \mathrm{~mL}$ of head space was sampled with a gas-tight syringe, and the $\mathrm{O}_{2}$ and $\mathrm{CO}_{2}$ concentrations were measured by gas chromatography (Varian 3800). The GC analysis conditions were column $=\mathrm{CTR} 1$ (Alltech, $3 \mathrm{~m}$ ); injector temperature $=120^{\circ} \mathrm{C}$; detector $(\mathrm{TCD})$ temperature $=120^{\circ} \mathrm{C}$; oven temperature $=35^{\circ} \mathrm{C}$; flow rate $=30 \mathrm{~mL} \cdot \mathrm{min}^{-1}$; and carrier gas $=\mathrm{He}$.

Measurement of vitamin $C$ content. The harvested sprouts were briefly washed with flowing tap water, and the tissues were separated into cotyledons and hypocotyls/roots. 
Table 1. Changes in the uptake of soaking solution and the fresh weight of soybean sprouts over $5 \mathrm{~d}$ of cultivation. Soybean seeds ( $1 \mathrm{~kg}$ ) were soaked in a solution containing water only (control), and $1,000 \mathrm{ppm}$ of low $(<10 \mathrm{kDa})$, medium $(20-50 \mathrm{kDa})$, or high $(>1,000 \mathrm{kDa}) \mathrm{molecular}$ weight chitosan for $3 \mathrm{~h}$ before cultivation. The data shown are the mean \pm standard deviation of three replications.

\begin{tabular}{|c|c|c|c|c|c|c|}
\hline $\begin{array}{l}\text { Molecular wt } \\
\text { of chitosan }\end{array}$ & $\begin{array}{c}\text { Soaking } \\
\text { solution } \\
\text { uptake }\end{array}$ & \multicolumn{5}{|c|}{ Fresh wt (g) } \\
\hline used in treatment & $\left(\mathrm{mL} \cdot \mathrm{kg}^{-1}\right)$ & $1 \mathrm{DAT}^{\mathrm{z}}$ & 2 DAT & 3 DAT & 4 DAT & 5 DAT \\
\hline Control & $818 a^{y}$ & $2,584 \pm 10.1 \mathrm{a}$ & $2,903 \pm 10.7 \mathrm{a}$ & $3,334 \pm 27.1 \mathrm{a}$ & $3,956 \pm 37.6 \mathrm{a}$ & $4,484 \pm 76.7 \mathrm{a}$ \\
\hline Low & $766 \mathrm{~b}$ & $2,606 \pm 7.0 \mathrm{ab}$ & $2,973 \pm 40.7 \mathrm{ab}$ & $3,480 \pm 95.6 b$ & $4,194 \pm 166.6 \mathrm{~b}$ & $4,774 \pm 115.0 b$ \\
\hline Medium & $736 \mathrm{c}$ & $2,588 \pm 11.1 \mathrm{a}$ & $2,968 \pm 19.5 \mathrm{ab}$ & $3,486 \pm 41.6 b$ & $4,242 \pm 37.9 \mathrm{~b}$ & $4,889 \pm 11.4 \mathrm{bc}$ \\
\hline High & 744 bc & $2,619 \pm 19.5 b$ & $3,025 \pm 55.2 \mathrm{~b}$ & $3,592 \pm 90.6 b$ & $4,379 \pm 109.6 \mathrm{~b}$ & $5,035 \pm 100.6 \mathrm{c}$ \\
\hline
\end{tabular}

${ }^{\mathrm{z}} \mathrm{DAT}=$ days after treatment

y Mean separation within columns by Duncan's multiple range test, $P \leq 0.05$.

Table 2. Effects of treatment with chitosan of low, medium, or high molecular weight on the growth of soybean sprouts. Soybean seeds were soaked for $3 \mathrm{~h}$ in solutions containing 1,000 ppm of chitosan prior to cultivation and measurements were made $5 \mathrm{~d}$ after treatments. The data shown are the means of at least 40 replicate measurements.

\begin{tabular}{lccccc}
\hline $\begin{array}{l}\text { Molecular wt of } \\
\text { used chitosan } \\
\text { in treatment }\end{array}$ & $\begin{array}{c}\text { Hypocotyl } \\
\text { length } \\
(\mathrm{cm})\end{array}$ & $\begin{array}{c}\text { Root } \\
\text { length } \\
(\mathrm{cm})\end{array}$ & $\begin{array}{c}\text { Hypocotyl to } \\
\text { root length } \\
\text { ratio }\end{array}$ & $\begin{array}{c}\text { Hypocotyl } \\
\text { thickness } \\
(\mathrm{mm})\end{array}$ & $\begin{array}{c}\text { No. of } \\
\text { lateral } \\
\text { roots (each) }\end{array}$ \\
\hline Control & $7.02 \mathrm{a}^{\mathrm{z}}$ & $3.97 \mathrm{a}$ & $1.77 \mathrm{c}$ & $1.58 \mathrm{a}$ & $1.75 \mathrm{a}$ \\
Low & $7.37 \mathrm{a}$ & $4.49 \mathrm{~b}$ & $1.64 \mathrm{bc}$ & $1.71 \mathrm{~b}$ & $2.17 \mathrm{a}$ \\
Medium & $7.41 \mathrm{a}$ & $4.72 \mathrm{~b}$ & $1.57 \mathrm{ab}$ & $1.71 \mathrm{~b}$ & $1.71 \mathrm{a}$ \\
High & $8.28 \mathrm{~b}$ & $5.31 \mathrm{c}$ & $1.56 \mathrm{a}$ & $1.66 \mathrm{ab}$ & $2.56 \mathrm{~b}$ \\
\hline
\end{tabular}

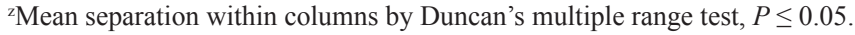

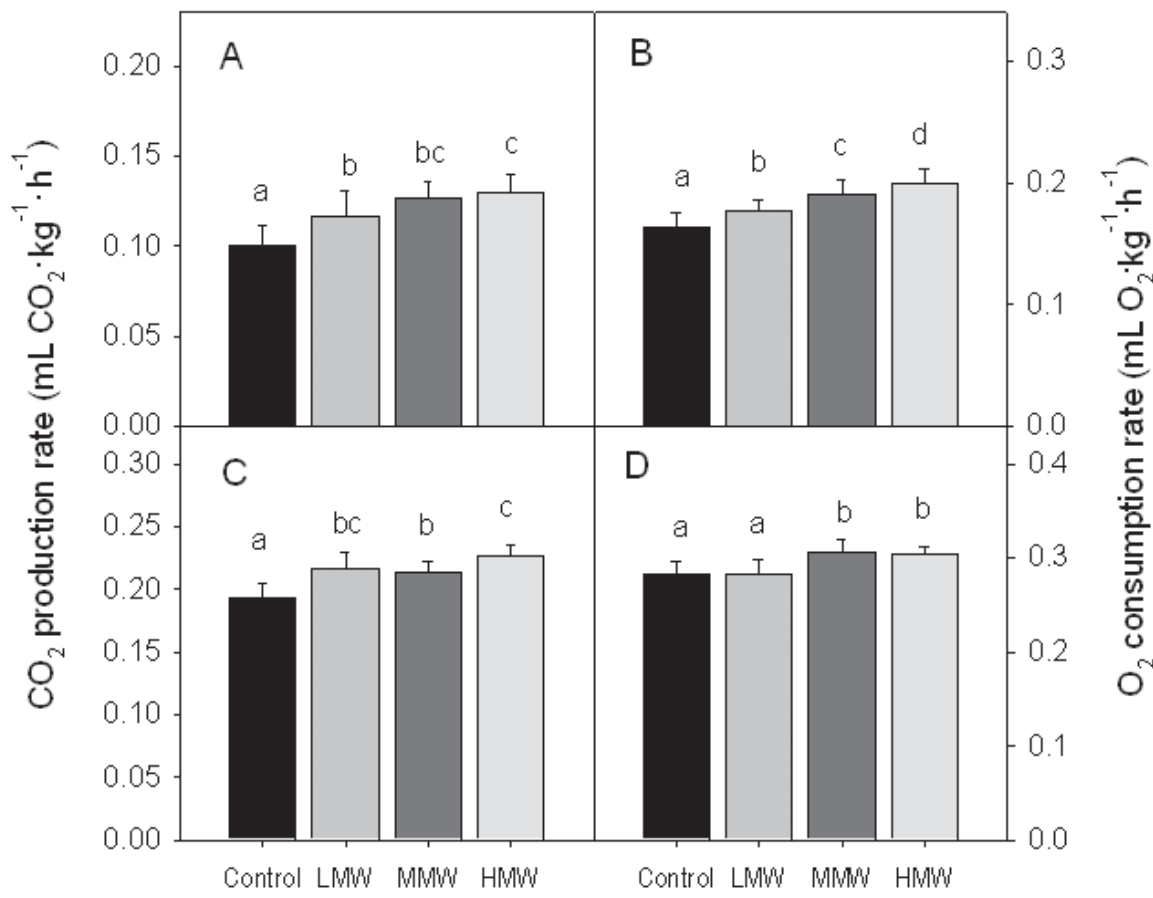

Fig. 1. Changes in $\mathrm{CO}_{2}$ production $(\mathbf{A}$ and $\mathbf{C})$ and $\mathrm{O}_{2}$ consumption (B and $\left.\mathbf{D}\right)$ of 1 -d-old (A and $\left.\mathbf{B}\right)$ and 3-d-old (C and D) soybean sprouts soaked with 1,000 ppm chitosan of low (LMW: $<10 \mathrm{kDa})$, medium (MMW: 20-50 kDa), or high (HMW: $>1,000 \mathrm{kDa}$ ) molecular weight. The data shown are the mean \pm standard deviation of three replications. (DMRT: $p<0.05$ ).

Five-gram samples of both portions were soaked in $5 \mathrm{~mL}$ of $10 \%$ metaphosphoric acid for $10 \mathrm{~min}$, homogenized with a mortar and pestle, and diluted to $50 \mathrm{~mL}$ with $5 \%$ metaphosphoric acid. After centrifugation at 3,000 rpm for 15 min, the supernatants were filtered through nylon syringe filters $(0.4 \mu \mathrm{m})$ and analyzed by HPLC (model S1211; Sykam, Germany) to assess the vitamin $\mathrm{C}$ content. The HPLC analysis conditions were mobile phase $=30 \%$ $\mathrm{MeOH}$ with $0.14 \%$ hexanesulfonic acid and $1 \%$ acetic acid; column $=250 \times 4.6 \mathrm{~mm}(5$ $\mu \mathrm{m}$ ) Luna $\mathrm{C} 18$; flow rate $=1.0 \mathrm{~mL} \cdot \mathrm{min}^{-1}$; and detection $=U V$ at $254 \mathrm{~nm}$. Each analysis was replicated at least three times.

Measurement of chlorophyll content. For chlorophyll measurement, the cotyledons were excised from the sprouts and dissected into two half-cotyledons under green safety lighting in a dark cultivation room. Twenty-five halfcotyledons were placed on a wet Whatman No. 2 filter paper in a petri dish, which was then covered with a glass lid. After exposure to fluorescent light (5,000 lux) for $5 \mathrm{~h}$ at room temperature, 20 representative half-cotyledons were selected, weighed, and immersed in 20 $\mathrm{mL}$ of $\mathrm{N}, \mathrm{N}-2,5$-dimethylformamide (DMF), and the tubes were completely wrapped with aluminum foil to prevent further exposure to light. After $20 \mathrm{~h}$ of shaking at $90 \mathrm{rpm}$ on an orbital shaker, the solutions were centrifuged and the absorbance of the supernatant was measured with a spectrophotometer (Thermoline). The chlorophyll contents were calculated using the equation of Moran (1982): chlorophyll a content $\left(\right.$ in $\left.\mu \mathrm{g} \cdot \mathrm{mL}^{-1}\right)=(12.81)\left(\mathrm{A}_{664}\right)-(2.16)\left(\mathrm{A}_{647}\right)$ $+(1.44)\left(\mathrm{A}_{625}\right)-(4.91)\left(\mathrm{A}_{603}\right)$.

Statistical analysis. Each experiment consisted of at least three independent replications. To determine the effects of chitosan treatment, Duncan's multiple range tests were applied to the data at the $5 \%$ level using the program SPSS (ver. 10.0, SPSS Institute, 2000).

\section{Results and Discussion}

Growth of soybean sprouts. The first step in seed germination, imbibition, is followed by the initiation of hydrolysis and the mobilization of storage reserves. Although the addition of chitosan slightly reduced the initial uptake of soaking solution (Table 1), the subsequent increase in fresh weight under cultivation conditions was accelerated in the presence of chitosan. The reason why solutions containing chitosan reduced initial imbitition is not clear; it may in part due to the decreased water potential by the presence of chitosan and subsequent reduced water potential gradient across seeds and soaking solution. Treatment with higher molecular weight chitosan induced the most rapid increase in fresh weight, resulting in a statistically significant increase in fresh weight as soon as $1 \mathrm{~d}$ after soaking, and treatment with medium or low molecular weight chitosan induced a significant increase in fresh weight by $3 \mathrm{~d}$ after treatment (Table 1). Soybean sprouts harvested after $5 \mathrm{~d}$ of cultivation exhibited a molecular-weight-dependent increase in fresh weight: high, medium, and low molecular weight chitosan increased the fresh weight by $12 \%, 9 \%$, and $6 \%$, respectively, as compared to the control. All of the growth parameters measured, including hypocotyl length, root length, and hypocotyl thickness, were also increased by chitosan treatment (Table 2). Such plant growth-enhancing effects of chitosan are consistent with previous reports (Kim, 1998 and references there in), although the precise mechanism of chitosan, especially of high molecular weight still 
remains to be elucidated. The increases in root growth were greater than the increases in hypocotyl growth. Higher molecular weight chitosan increased the root length by $34 \%$ and the hypocotyl length by $18 \%$ as compared to the control, resulting in a hypocotyl length to root length ratio of 1.56 , as compared to 1.77 in the control. Hypocotyl thickness was also increased by chitosan treatment. An increase in the number of lateral roots by treatment with high molecular weight chitosan was the only adverse effect of chitosan treatment, in that consumers tend to prefer sprouts without lateral roots. Therefore, cultural practices that prevent lateral root formation, such as more frequent irrigation (Park and Kim, 1998), should be used when treating soybean seeds with chitosan.

Respiration of soybean sprouts. The respiration rate of growing soybean sprouts was measured to understand the mechanism of the growth-enhancing effects of chitosan. Chitosan increased both the $\mathrm{CO}_{2}$ production and the $\mathrm{O}_{2}$ consumption of sprouts, and these effects were proportional to the molecular weight of chitosan used (Fig. 1), as shown by the fresh weight and other growth parameters. The enhanced respiration rate and consequent increased respiration heat may increase the temperature inside the cultivation vessel (Lee, 2000), resulting in the stimulation of sprout growth. The respiration-enhancing effects of chitosan were rapid: a $30 \%$ increase in $\mathrm{CO}_{2}$ production occurred within $1 \mathrm{~d}$, after soaking in a solution of high molecular weight chitosan. Even treatment with low molecular weight chitosan resulted in significantly increased $\mathrm{CO}_{2}$ production (by 17\%) and $\mathrm{O}_{2}$ consumption (by $8 \%$ ) at $1 \mathrm{~d}$ after soaking. However, by $3 \mathrm{~d}$ after soaking, the respiration-increasing effects of chitosan were less prominent, with high molecular weight chitosan increasing the $\mathrm{CO}_{2}$ production by $17 \%$. These results indicate that the previously observed growth-enhancing effects of chitosan treatment may result from an increased respiration rate, especially during the initial stage of soybean sprout growth after soaking. The fact that chitosan in soaking solution retarded initial imbibition (Table 1) might be a beneficial factor because excessive imbibition, especially at high temperature as well as accelerated hydration, especially in soybean seeds with split seed coat may decrease germination viability resulting in yield loss of sprouts (Kim et al., 1988; Park et al., 1994; Park and Kim, 1998). However, the precise mechanism underlying the respiration-enhancing effects of chitosan remains to be elucidated.

Vitamin C content and chlorophyll formation. As vitamin $\mathrm{C}$ is an important nutritional factor in soybean sprouts, the effects of chitosan on the vitamin $\mathrm{C}$ content of harvested soybean sprouts were evaluated. Although no statistically significant changes were observed, soaking soybean seeds in chitosan-containing solutions induced a tendency toward slightly reduced vitamin $\mathrm{C}$ content, proportional to the molecular weight of chitosan used, in both cotyledons (cont, $16.4 \mathrm{mg} / 100 \mathrm{~g}$; LMW, 15.7 mg/100 g; MMW, 14.8 mg/100 g; HMW, 14.3 $\mathrm{mg} / 100 \mathrm{~g}$ ) and hypocotyls/roots (cont, 10.1 mg/100 g; LMW, 8.5 mg/100 g; MMW, 7.9 $\mathrm{mg} / 100 \mathrm{~g}$; HMW, $7.8 \mathrm{mg} / 100 \mathrm{~g}$ ). The slight reduction in vitamin $\mathrm{C}$ content, especially in the hypocotyl and root samples, may be due in part to dilution effects; the vitamin $\mathrm{C}$ content was expressed based on the fresh weight, and there were significant increases in the fresh weight and water content after chitosan treatment (Park and Kim, 2003).

Traditionally, soybean sprouts have been sold in the market packaged in the original cultivation container. However, recent changes in customer preferences have increased the circulation of sprouts packaged in transparent film, which increases the extent of light-dependent greening resulting from chlorophyll formation in the cotyledons (Kasemir, 1983). Unfortunately, the greening of the cotyledons limits the marketability of sprouts. To clarify the effects of chitosan on postharvest chlorophyll formation, harvested soybean sprouts were exposed to fluorescence light. Regardless of the molecular weight used, chitosan treatment induced no statistically significant changes in the chlorophyll content of cotyledons (content $=3.7 \mu \mathrm{g} \cdot \mathrm{g}^{-1} ; \mathrm{LMW}=2.9 \mu \mathrm{g} \cdot \mathrm{g}^{-1} ; \mathrm{MMW}=3.0$ $\mu \mathrm{g} \cdot \mathrm{g}^{-1} ; \mathrm{HMW}=3.0 \mu \mathrm{g} \cdot \mathrm{g}^{-1}$ ), suggesting that chitosan does not affect chlorophyll formation. These results were in agreement with the previously described increase in respiration induced by chitosan, in that the effects of chitosan were more prominent during the early stage of germination and became less significant with the extension of the cultivation period following treatment. In conclusion, it is very likely that soaking soybean seeds in a solution containing $1,000 \mathrm{ppm}$ chitosan of high molecular weight is a practical method to enhance the respiration, growth, and resultant productivity of soybean sprouts.

\section{Literature Cited}

Bhaskara Reddy, M.V., P. Angers, F. Castaigne, and J. Arul. 2000. Chitosan effects on blackmold rot and pathogenic factors produced by Alternaria alternata in postharvest tomatoes. J. Amer. Soc. Hort. Sci. 125:742-747.

El Ghaouth, A., J. Arul, A. Asselin, and N. Benhamous. 1992. Antifungal activity of chitosan on post harvest pathogens: Induction of morphological and cytological alterations in Rhizopus stolonifer. Mycol. Res. 96:769-779.

Jeon, Y.J., E.H. Lee, and S.K. Kim. 1996. Bioactivities of chitin and chitosan (1) Antimicrobial function, hypertension control function and cholesterol control function. J. Chitin Chitosan 1:4-13.

Jo, H.L. 1989. Antimicrobial activity and food preservative function of a low molecular weight chitosan. PhD thesis. Busan Natl. Fisheries Univ., Korea.

Kasemir, H. 1983. Light control of chlorophyll accumulation in higher plants, p. 662-686. In: W. Shropshire, Jr, and H. Mohr (eds.). Encyclopedia of plant physiology. New Ser. vol. 6B. Photomorphogenesis. Springer-Verlag, New York.

Kendra, D.F., and L.A. Hadwiger. 1984. Characterization of the smallest chitosan oligomer that is maximally antifungal to Fusarium solaniand elicits pisatin formation in Pisum sativum. Expt. Mycol. 8:276-278.

Kim, J.G., W.J. Kim, and S.K. Kim, 1988. Hydration properties of Korean soybeans. Kor. J. Food Sci. Technol. 20:256-262.

Kim, S.K. 1998. Application of chitin and chitosan in agriculture. J. Chitin Chitosan 3:327-342.

Kim, S.D., S.H. Kim, and E.H. Hong. 1993. Composition of soybean sprout and its nutritional value. Kor. Soybean Dig. 10:1-9.

Kim, S.K., Y.J. Jeon, and H.C. Zan. 2000. Antibacterial effect of chitooligosaccharides with different molecular weights prepared using membrane bioreactor. J. Chitin Chitosan 5:1-8.

Lee, Y.S. 2000. Utilization of ventilation pipe to decrease commodity temperature and rot of soybean sprouts. J. Bio-Environ. Control 9:101-106.

Lee, Y.S., C.S. Kang, and Y.S Lee. 1999. Effects of chitosan on production and rot control of soybean sprouts. Kor. J. Crop Sci. 44:368-372.

Moran, R. 1982. Formulae for determination of chlorophyllous pigments extracted with N,N-Dimethylformamide. Plant Physiol. 69:1376-1381.

Park, I.K. and S.D. Kim. 2003. Sugar and free amino acid content of chitosan-treated soybean sprouts. J. Chitin Chitosan 8:105-110.

Park, K.Y., S.D. Kim, and Y.H. Ryu. 1994. Water uptake, cotyledon damage after imbibition and hypocotyl elongation in soybean with different seed size and clolor. Kor. J. Crop Sci. 39:331-338.

Park, W.M. and J.H. Kim. 1998. Effects of watering on yield of soybean sprout. Kor. Soybean Dig. 15:46-57.

Yun, Y.S., K.S. Kim, and Y.N. Lee. 1999. Antibacterial and antifungal effect of chitosan. J. Chitin Chitosan 4:8-14. 